\title{
A organização em rede dos catadores de materiais recicláveis na cadeia produtiva reversa de pós-consumo da região da grande Florianópolis: uma alternativa de agregação de valor
}

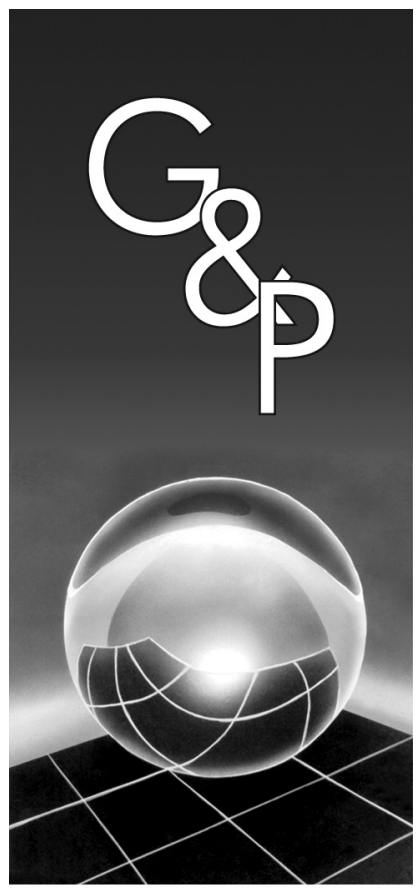

Israel Fernandes de Aquino Armando Borges de Castilho Jr. Thyrza Schlichting De Lorenzi Pires

\section{Resumo}

Este trabalho relata a pesquisa realizada sobre integrantes da cadeia produtiva reversa de pós-consumo da região da grande Florianópolis, Santa Catarina, Brasil. Tem-se como objetivo propor uma forma de organização logística para as associações de catadores de materiais recicláveis realizarem a comercialização direta de seus produtos às indústrias recicladoras, visando à agregação de valor. Os resultados da pesquisa mostraram que a partir da organização das associações de catadores em rede, todas elas conseguiriam comercializar produtos diretamente com indústrias recicladoras, e, juntas, obteriam uma agregação de $32 \%$ no valor dos produtos comercializados.

Palavras-chaves: Catador. Materiais recicláveis. Rede. Logística reversa.

\section{Introdução}

A coleta seletiva no Brasil é organizada basicamente pelo setor privado, visando-se a reciclagem industrial. $\mathrm{Na}$ base do sistema, estão os catadores de materiais recicláveis que realizam essa atividade, na maioria dos casos, informal, sem o devido apoio dos órgãos públicos responsáveis pela gestão dos resíduos sólidos e pelos principais beneficiários da cadeia da reciclagem que são os sucateiros e as indústrias (CONCEIÇÃO, 2003). A cadeia da reciclagem é formada pelos catadores, sucateiros de pequeno porte, sucateiros de grande porte e industriais (CALDERONI, 1999).

Os integrantes da cadeia de reciclagem que menos se beneficiam com esta atividade são os catadores. Isso ocorre porque as indústrias que compram materiais recicláveis são poucas, formando um mercado oligopsônico, ou seja, com poucos compradores que puxam o preço dos recicláveis para baixo. Além disso, as indústrias só compram materiais em grandes quantidades e com boa qualidade (GONÇALVEZ, 2003). Essas condições normalmente são satisfeitas somente pelos grandes sucateiros que possuem infraestrutura e equipamentos adequados e compram os materiais em pequenas quantidades dos catadores. Estes, por sua vez, geralmente se encontram dispersos, sem condições de negociar diretamente com a indústria e com pouco poder perante os sucateiros.
A coleta seletiva na região da grande Florianópolis é prioritariamente realizada pelo setor informal, visto que 90\% da quantidade de materiais recicláveis recolhidos pelos sistemas de coleta seletiva, incluindo-se os setores formal e informal, é realizada pelos catadores, configurando-se como numa cadeia nos moldes da descrita anteriormente. Envolvidos nesse sistema, estima-se que existam aproximadamente 920 catadores trabalhando diretamente nas coletas seletivas realizadas nas cidades de Florianópolis, São José, Palhoça, Biguaçu e Tijucas, desviando dos locais de destinação final de resíduos em torno de $13 \%$ da quantidade gerada de resíduos sólidos domésticos nesta região. Porém, apesar da relevância da atividade dos catadores nesses municípios, trazendo benefícios sociais, econômicos e ambientais, esses trabalhadores são pouco valorizados (AQUINO, 2007).

Como alternativa para os catadores obterem maiores benefícios com a sua participação na cadeia da reciclagem, aponta-se o caminho da organização deles em empreendimentos autogestionários e a articulação destes em redes ou federações. Dessas ações advêm benefícios de ordem social e também econômica que ocorrem por meio da agregação de valor aos materiais recicláveis recolhidos pelos catadores através da verticalização de seus negócios. Isso inclui a diversificação 
das atividades por meio da transformação do material reciclável e a comercialização direta de seus produtos (REINFELD, 1994; RODRIGUEZ, 2002). No intuito de percorrer esse caminho, várias iniciativas foram feitas, expressando-se na formação de inúmeros empreendimentos autogestionários e redes de catadores em todo o Brasil. Na região de Florianópolis, por exemplo, há algumas iniciativas de associativismo entre os catadores de materiais recicláveis.

Apesar destas iniciativas organizacionais, sabe-se que a maioria dos catadores não está associada entre si, mas vinculados a outros intermediários, bem como muitos dos empreendimentos formados não conseguem desenvolver as estratégias apontadas para a agregação de valor aos produtos comercializados pelos catadores. Dessa situação advém a seguinte questão: considerando o atual sistema da cadeia da reciclagem, como as associações de catadores de materiais recicláveis da região da grande Florianópolis podem se organizar para comercializarem seus produtos diretamente com as indústrias recicladoras? Buscando resposta à esta questão, o presente trabalho tem como objetivo propor uma alternativa de organização logística para as associações de catadores de materiais recicláveis dessa região. a fim de propiciar a comercialização direta de produtos junto às indústrias recicladoras, visando à agregação de valor aos materiais comercializados pelos catadores.

\section{Método}

Tendo-se em vista a necessidade de se explorar e descrever a cadeia produtiva reversa de pós-consumo na região da grande Florianópolis para propor uma forma de organização logística aos empreendimentos de catadores de materiais recicláveis da referida região, e considerando-se as características deste objeto de pesquisa, utilizou-se como procedimento metodológico fundamental a pesquisa de levantamento ou survey (SCHMID, 2006). A pesquisa possui duas etapas básicas, conforme pode ser observado na Figura 1.

\subsection{Diagnóstico}

\subsubsection{Caracterização da região de estudo}

$\mathrm{Na}$ caracterização da região de estudo, foram levantadas informações por meio de pesquisa bibliográfica. A região de estudo referente aos integrantes da base da cadeia produtiva reversa de pós-consumo envolveu os municípios catarinenses: Florianópolis, São José, Palhoça, Biguaçu e Tijucas. Nestas cidades, foram coletados dados sobre a localização geográfica, a área territorial, a geografia, a população e a economia. Já a região referente às indústrias recicladoras, localizadas na ponta da cadeia, englobou os Estados do RS, SC, PR e SP. Nesta região de estudo, buscou-se localizar os principais pólos de reciclagem.

\subsubsection{Caracterização dos resíduos sólidos e de seu gerenciamento}

$\mathrm{Na}$ caracterização dos resíduos sólidos e de seu gerenciamento, foram obtidos dados sobre a geração e o gerenciamento de resíduos sólidos de características domésticas na região de estudo referente à base da cadeia. O levantamento de dados ocorreu por meio de aplicação de formulários junto aos funcionários do setor de limpeza pública das prefeituras e pesquisa bibliográfica.

\subsubsection{Caracterização da cadeia produtiva reversa de pós-consumo}

Para melhor compreensão da etapa de caracterização da cadeia produtiva reversa de pós-consumo apresentam-se abaixo algumas definições utilizadas nesta pesquisa:

a) catador de material reciclável: segundo a classificação brasileira de ocupações de 2002, o(a) catador(a) de material reciclável é aquele(a) trabalhador(a) que cata, seleciona e vende materiais recicláveis como papel, papelão, plástico e vidro, bem como materiais ferrosos e não ferrosos e outros materiais reaproveitáveis;

b) intermediário: é uma organização que realiza geralmente a compra e a venda de materiais recicláveis como papel, papelão, plástico e vidro, bem como materiais ferrosos e não ferrosos e outros materiais reaproveitáveis. Algumas organizações, porém, não realizam a compra dos materiais recicláveis. Entre as demais atividades desenvolvidas por intermediários

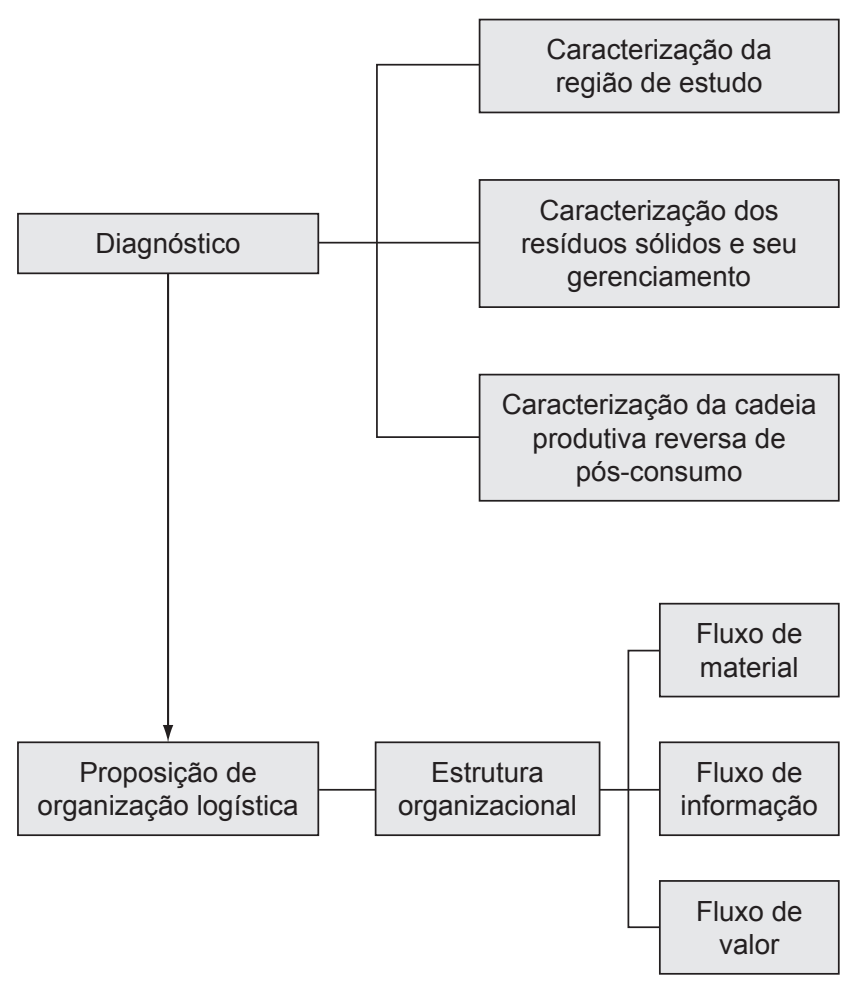

Figura 1. Fluxograma das etapas da pesquisa. 
estão: a coleta, a pesagem, a triagem, a trituração, a prensagem, a armazenagem e o transporte de materiais. Como intermediário, classificam-se associações e cooperativas de catadores, além de empresas com fins lucrativos formais e informais; e

c) indústria recicladora: é uma organização que realiza a transformação de material reciclável.

A coleta de dados foi realizada por meio de revisão bibliográfica sobre os catadores de materiais recicláveis da região, de entrevistas estruturadas junto a vinte e sete intermediários, dentre eles quatro associações de catadores, bem como por meio de entrevistas estruturadas e aplicação de questionários junto a dez indústrias recicladoras de papéis, dezesseis de plásticos, uma de vidros, duas de metais ferrosos e uma de alumínios, no período de julho a novembro de 2006. Sobre os intermediários e indústrias recicladoras foram coletados os dados contidos no Quadro 1.

A descrição dos dados iniciou-se com a tabulação deles. A partir da análise dos dados, realizou-se uma classificação dos intermediários da cadeia produtiva reversa de pós-consumo da região de estudo em grupos, em função da semelhança de características, tendo-se como referenciais básicos os clientes das organizações e a quantidade de material processada. A classificação adotada possui os critérios contidos no Quadro 2.

A partir de fluxogramas específicos e da tabulação dos dados obtidos por meio das entrevistas e questionário desenhou-se e descreveu-se um fluxograma genérico que represente a cadeia produtiva reversa de pós-consumo na região de estudo (LEITE, 2003). Para caracterização dos integrantes da cadeia, foram apresentados alguns resul-

Quadro 1. Dados coletados junto aos intermediários e indústrias recicladoras.

\begin{tabular}{|cc|}
\hline Intermediários & Indústrias recicladoras \\
Tipo de organização & Materiais comercializados \\
Materiais comercializados & Preços praticados \\
Preços praticados & Exigências de quantidade \\
Quantidade de material & Exigências de \\
processada & qualidade \\
Atividades & Exigências de \\
desenvolvidas & frequiência de entrega \\
Número de & Condições para \\
trabalhadores envolvidos & realizar parcerias \\
Infra-estrutura e & Forma de \\
equipamentos utilizados & transporte \\
Forma de transporte & Forma de pagamento \\
Exigências aos fornecedores & Quantidade de \\
Área de atuação/abrangência & Produto final comercializado \\
Compradores & \\
Forma de pagamentos & \\
Dificuldades e limitações & \\
\hline
\end{tabular}

tados da análise dos dados de cada grupo, buscando-se evidenciar suas características.

Para avaliar a possibilidade de associações de catadores avançarem na cadeia produtiva reversa de pósconsumo, sugeriram-se critérios para verificar a posição que determinada organização ocupa na cadeia, bem como se identificaram fatores que precisam ser observados em uma organização para avaliar sua possibilidade de desenvolver-se e avançar na cadeia.

Nesta etapa, também se realizou a avaliação da possibilidade das associações de catadores identificadas na região de estudo avançarem na cadeia produtiva reversa de pós-consumo. Num primeiro momento, analisou-se individualmente cada uma das associações, em seguida, analisou-se seu conjunto. Para tanto, além da observação dos fatores influentes no desenvolvimento dos integrantes da cadeia, realizou-se um estudo econômico sobre a comercialização direta entre as associações de catadores e indústrias recicladoras.

Este estudo foi realizado analisando-se dados das associações de catadores e das indústrias recicladoras que teriam suas exigências quantitativas atendidas, bem como ofereceram os melhores preços e condições aos seus fornecedores. Nesta análise econômica, foram considerados os preços de venda e as quantidades dos materiais recicláveis das associações, os preços dos recicláveis pagos pelas indústrias, bem como os custos com transporte de carga, os tributários e os financeiros.

\subsection{Proposição de organização logística}

Nesta etapa, indicou-se uma forma de organização logística para as organizações de catadores realizarem, em rede, a comercialização direta de seus produtos às indústrias recicladoras. Para tanto, foi sugerida uma estrutura organizacional, bem como a indicação dos fluxos de materiais recicláveis, de informações e de valor. Essa proposição teve como base, além da realidade da cadeia produtiva reversa de pós-consumo pesquisada, as estratégias logísticas adotadas por outras organizações de catadores.

Sobre o modelo proposto, realizou-se estudo econômico para avaliar a viabilidade econômica do empreendimento. A avaliação foi realizada considerando-se a Rede como uma associação. Para tanto, se considerou o capital de investimento necessário para implantação da Rede, seus custos de produção e financeiros e suas receitas.

Quadro 2. Critérios de classificação dos intermediários.

\begin{tabular}{|cc|}
\hline $\begin{array}{c}\text { Classe de intermediário } \\
\text { Intermediário nível 1 }\end{array}$ & $\begin{array}{c}\text { Critério de classificação } \\
\text { Vende para intermediários e } \\
\text { para até uma indústria recicladora }\end{array}$ \\
Intermediário nível 2 & $\begin{array}{c}\text { Vende para intermediários e/ou para } \\
\text { mais de uma indústria recicladora }\end{array}$ \\
Intermediário nível 3 & $\begin{array}{c}\text { Vende somente para } \\
\text { indústria(s) recicladora(s) e } \\
\text { processa no mínimo 100 t/m }\end{array}$ \\
&
\end{tabular}


Os itens de capital de investimento incluídos nos cálculos foram os equipamentos e as edificações. Os custos com terrenos foram considerados nulos, vistos estes serem considerados de utilidade pública e cedidos pela municipalidade. Os custos de produção na rede, considerada como associação, incluiu gastos com coleta e transporte de materiais, bem como com energia elétrica. A remuneração dos associados foi calculada após desconto das despesas das receitas, sendo considerado o pagamento da seguridade social.

$\mathrm{O}$ custo financeiro da associação refere-se ao financiamento do capital investido com juros de $12 \%$ a.a. As receitas consideradas foram as possíveis de serem obtidas com a venda de papéis e plásticos para indústrias recicladoras e de vidros e metais para intermediários, bem como o repasse pela Prefeitura dos custos evitados em função do trabalho dos catadores. Para análise de viabilidade da rede como uma associação, compararam-se as sobras/ rendimentos dos catadores organizados em rede com as suas sobras/rendimentos atuais.

\section{Resultados}

\subsection{Diagnóstico}

\subsubsection{Caracterização da região de estudo}

A região de estudo referente à base da cadeia produtiva reversa de pós-consumo localiza-se no litoral centro do Estado de Santa Catarina/Brasil, que possui, além da planície litorânea e dos vales dos rios, áreas com declividades acentuadas. A referida região abrange uma área de $1543 \mathrm{~km}^{2}$, com uma população estimada de 800.691 habitantes no ano de 2005, tendo sua economia baseada no setor de serviços e comércio. Os municípios dessa região foram classificados como urbanos visto que a percentagem da população urbana ultrapassa $80 \%$ da população total. Sobre a região de estudo referente aos integrantes da ponta da cadeia, verificou-se que os polos de reciclagem localizam-se conforme descrito no Quadro 3:

\subsubsection{Caracterização dos resíduos sólidos e de seu gerenciamento}

Aproximadamente 87\% (17.200 t/m) dos resíduos sólidos domiciliares gerados $(19.750 \mathrm{t} / \mathrm{m})$, são recolhidos pelas coletas convencionais realizadas indiretamente pelas prefeituras e encaminhados a um aterro sanitário de propriedade

Quadro 3. Localização dos polos de reciclagem.

\begin{tabular}{|ccccc|}
\hline Polos de reciclagem & RS & SC & PR & SP \\
Plásticos & $\mathrm{x}$ & $\mathrm{x}$ & $\mathrm{x}$ & $\mathrm{x}$ \\
Papéis & & $\mathrm{x}$ & $\mathrm{x}$ & $\mathrm{x}$ \\
Vidros & $\mathrm{x}$ & & & $\mathrm{x}$ \\
Alumínio & $\mathrm{x}$ & & & $\mathrm{x}$ \\
Ferrosos & $\mathrm{x}$ & & $\mathrm{x}$ & $\mathrm{x}$ \\
\hline
\end{tabular}

particular, localizado no município de Biguaçu. O índice de cobertura da coleta convencional é superior a $90 \%$ e o custo de coleta, transporte e aterramento de resíduos sólidos praticado pelas municipalidades é de pelo menos R $\$ 135 /$ t.

Os demais 13\% (2.550 t/m) dos resíduos sólidos gerados são encaminhados para reciclagem através da coleta realizada pelos catadores ou pela coleta seletiva porta a porta realizada pelas prefeituras de Florianópolis e São José. Porém, destaca-se que, da quantidade de material encaminhada para reciclagem, $90 \%(2.300 \mathrm{t} / \mathrm{m})$ é realizada pelos catadores, e $10 \%(250 \mathrm{t} / \mathrm{m})$ é realizada pelas prefeituras citadas.

Estima-se que a coleta seletiva desenvolvida pelos catadores envolve diretamente 920 pessoas, que, usando carrinhos, carroças, bicicletas, ou mesmo a pé e com um saco, coletam os materiais recicláveis pré-selecionados ou não, disponibilizados pelos geradores de resíduos sólidos domiciliares. Após os materiais recicláveis serem coletados pelas prefeituras e catadores, eles são encaminhados para intermediários, que, por sua vez, os encaminham às recicladoras, que, por fim, fazem os materiais retornarem para consumo.

Com base nos resultados da caracterização dos resíduos domiciliares de Florianópolis realizada pela COMCAP, 2002, estima-se que $36 \%$ em peso dos resíduos domiciliares coletados sejam materiais passíveis de serem reciclados. Esse percentual equivale a uma quantidade mensal de 6.192 toneladas de materiais recicláveis que são encaminhados para disposição final pelas cidades da região de estudo. Considerando-se a quantidade de material que é encaminhada para reciclagem, estima-se que $29 \%$ em peso da quantidade de resíduos sólidos passíveis de serem reciclados são recuperados pelos catadores e pelas coletas seletivas das prefeituras.

\subsubsection{Caracterização da cadeia produtiva reversa de pós-consumo}

Como representação da cadeia produtiva reversa de pós-consumo na região da grande Florianópolis, apresenta-se a Figura 2.

Os resíduos sólidos recicláveis gerados podem se movimentar por diferentes caminhos, passando por 1 até 4 integrantes, antes de serem reciclados e consumidos novamente. Os recicláveis podem ser coletados de várias formas, bem como encaminhados à residência do catador, ao intermediário nível 1, ou ainda ao intermediário nível 2. Apesar dos intermediários nível 2 adquirirem materiais diretamente de catadores, geralmente o primeiro intermediário a comprar os matérias recicláveis é o de nível 1 , visto esta classe de intermediário estar em maior número no mercado. Entre os 27 intermediários entrevistados na pesquisa, 13 foram classificados como de nível 1, 7, de nível 2 e, outros 7, de nível 3.

Constatou-se que dos 20 intermediários níveis 1 e 2, que estão na base da cadeia, 17 envolvem diretamente o trabalho dos catadores de materiais recicláveis na etapa 
de coleta, 2 envolvem indiretamente, e, apenas 1, não envolve os catadores. Portanto, a forma mais comum de coleta de materiais recicláveis entre os geradores e os intermediários níveis 1 e 2 é aquela realizada pelos catadores, sozinhos ou em parceria com os intermediários.

Em relação às indústrias recicladoras, apresentam-se no Quadro 4 as exigências feitas a seus fornecedores de materiais recicláveis. Para ilustrar como geralmente os preços pagos aos fornecedores são maiores quanto mais se avança na cadeia, no sentido intermediário nível $1 \rightarrow$ recicladora, apresentam-se as Figuras 3 e 4 com os preços frequentemente pagos pelos diversos níveis de intermediários e recicladoras, aos fornecedores de papel ondulado, papel branco, papel misto, PET, PEAD duro natural e PEBD mole cristal. Também se podem observar por esses gráficos que as classes estabelecidas para o agrupamento dos intermediários foram bem definidas.

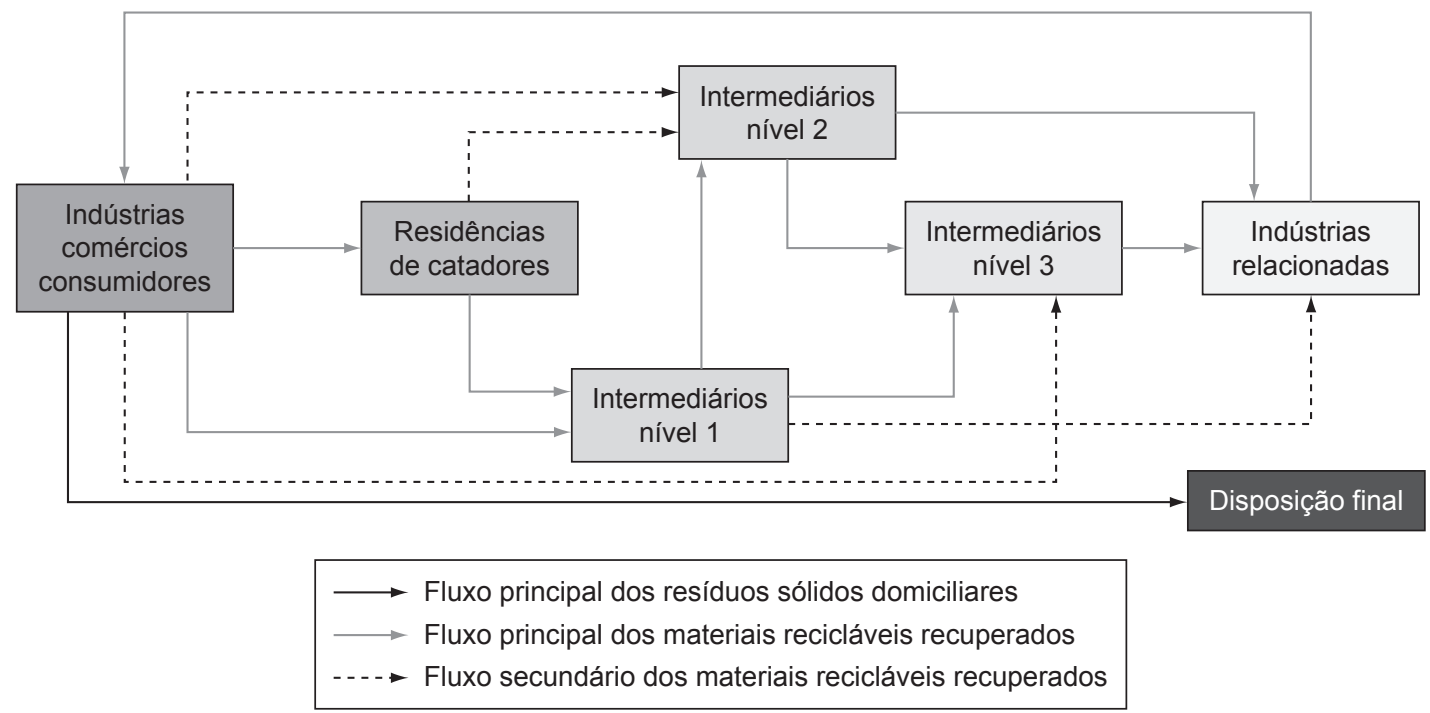

Figura 2. Fluxograma genérico da cadeia produtiva reversa de pós-consumo na região da grande Florianópolis.

Quadro 4. Resumo das exigências geralmente impostas pelas recicladoras aos seus fornecedores.

\begin{tabular}{|c|c|c|c|c|c|}
\hline Exigências & $\begin{array}{c}\text { Recicladora de } \\
\text { papel }\end{array}$ & $\begin{array}{l}\text { Recicladora de } \\
\text { plástico }\end{array}$ & $\begin{array}{l}\text { Recicladora de } \\
\text { alumínio }\end{array}$ & Recicladora de vidro & $\begin{array}{l}\text { Recicladora de } \\
\text { metal ferroso }\end{array}$ \\
\hline $\begin{array}{l}\text { Qualidade do } \\
\text { material }\end{array}$ & $\begin{array}{c}\text { TU }(\%): 10-15 \\
\text { TI }(\%): 0,5-5 \\
\text { TM (\%): } 0,5-1\end{array}$ & $\begin{array}{l}1 \% \text { a } 5 \% \text { de impu- } \\
\text { rezas no máximo }\end{array}$ & $\begin{array}{c}\text { Especificações da } \\
\text { classificação de sucata } \\
\text { de alumínio da ABAL }\end{array}$ & $\begin{array}{l}\text { Vidro em cacos e com } \\
20 \% \text { de impureza no } \\
\text { máximo }\end{array}$ & $\begin{array}{c}\text { Permitem-se impurezas } \\
\text { intrínsecas aos } \\
\text { materiais ferrosos }\end{array}$ \\
\hline $\begin{array}{l}\text { Quantidade mínima de } \\
\text { material fornecida }\end{array}$ & $\begin{array}{c}12 \text { a } 14 \text { toneladas } \\
\text { por carga }\end{array}$ & $\begin{array}{c}\text { Variável: } \\
300 \text { a } 12.000 \mathrm{~kg} \\
\text { por carga }\end{array}$ & $\begin{array}{l}\text { Uma tonelada de } \\
\text { determinado tipo de } \\
\text { material por carga }\end{array}$ & $\begin{array}{c}50 \mathrm{t} / \mathrm{m} \text { com } \\
\text { perspectiva de au- } \\
\text { mento }\end{array}$ & $\begin{array}{l}10 \text { toneladas } \\
\text { por carga }\end{array}$ \\
\hline $\begin{array}{l}\text { Frequência mínima de } \\
\text { entrega }\end{array}$ & Não há & Não há & Mensal & Mensal & Mensal \\
\hline Enfardamento & Não especifica & $\begin{array}{l}\text { Peso máx. de } \\
250 \mathrm{~kg}\end{array}$ & $\begin{array}{c}\text { Conforme } \\
\text { classificação da sucata }\end{array}$ & - & Sem especificação \\
\hline $\begin{array}{l}\text { Cumprimento do pra- } \\
\text { zo de entrega acordado }\end{array}$ & Exige & Exige & Exige & - & - \\
\hline $\begin{array}{l}\text { Emissão de nota } \\
\text { fiscal pelo fornecedor }\end{array}$ & Exige & Exige & - & Exige & Exige \\
\hline $\begin{array}{l}\text { Responsabilidade } \\
\text { sobre o transporte }\end{array}$ & $\begin{array}{l}\text { Variável: fornece- } \\
\text { dor ou recicladora }\end{array}$ & $\begin{array}{l}\text { Variável: fornece- } \\
\text { dor ou recicladora }\end{array}$ & Fornecedor & Fornecedor & $\begin{array}{l}\text { Geralmente o } \\
\text { fornecedor }\end{array}$ \\
\hline $\begin{array}{l}\text { Tempo de pagamento } \\
\text { ao intermediário }\end{array}$ & $\begin{array}{l}\text { Paga geralmente } \\
\text { em } 30 \text { ou } 60 \text { dias }\end{array}$ & $\begin{array}{l}\text { Paga geralmente } \\
\text { em } 10 \text { ou } 30 \text { dias }\end{array}$ & $\begin{array}{l}\text { Paga adiantado, } \\
\text { a prazo ou à vista }\end{array}$ & Paga em 15 dias & Paga à vista \\
\hline
\end{tabular}

Obs.: TU (\%):teor de umidade; TI (\%): teor de impureza (papéis, cartões e papelões inadequados para a utilização em uma determinada finalidade, ou outros tipos de materiais como metais, plásticos, vidro, etc); e TM (\%): teor de materiais proibitivos (papel vegetal, papel e papelão encerados e parafinados, papel carbono, papel e papelão impregnados com substâncias impermeáveis à umidade e colas a base de resinas sintéticas). 
A - Avaliação da possibilidade de determinados integrantes avançarem na cadeia produtiva reversa de pós-consumo

A primeira ação para avaliar a possibilidade de uma determinada organização avançar na cadeia produtiva reversa de pós-consumo é identificar o nível de intermediário em que se encontra. Para tanto, se utilizam os mesmos critérios descritos na etapa para classificar os diversos intermediários pesquisados, descritos no Quadro 2, seção 2.1.3. Após essa localização, deve-se analisar a organização em questão para conhecer quais as limitações que a impedem de avançar no nível de intermediário, ou ao menos melhorar sua situação sem necessariamente avançar na cadeia.

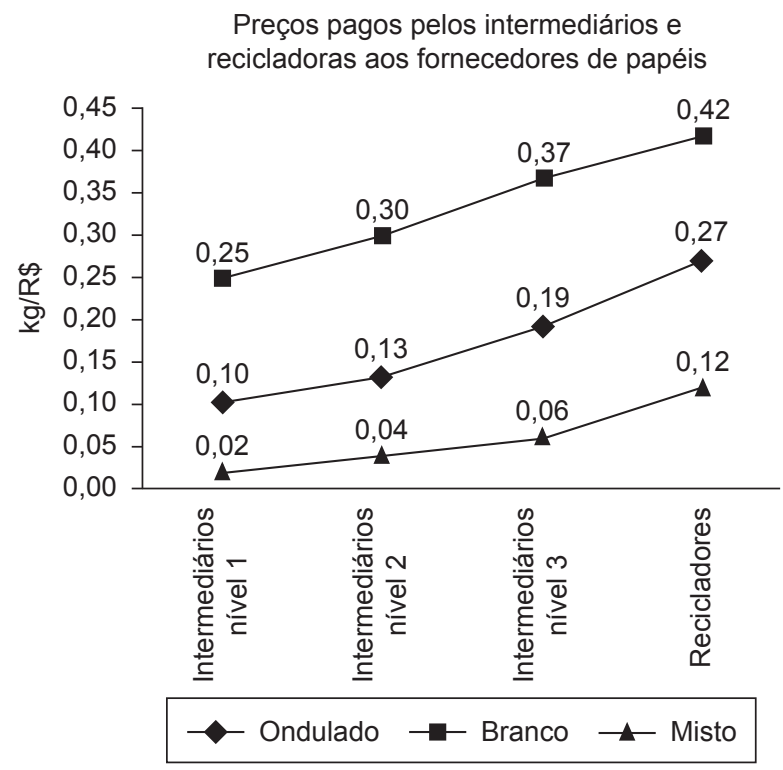

Figura 3. Preços pagos aos fornecedores de papéis.

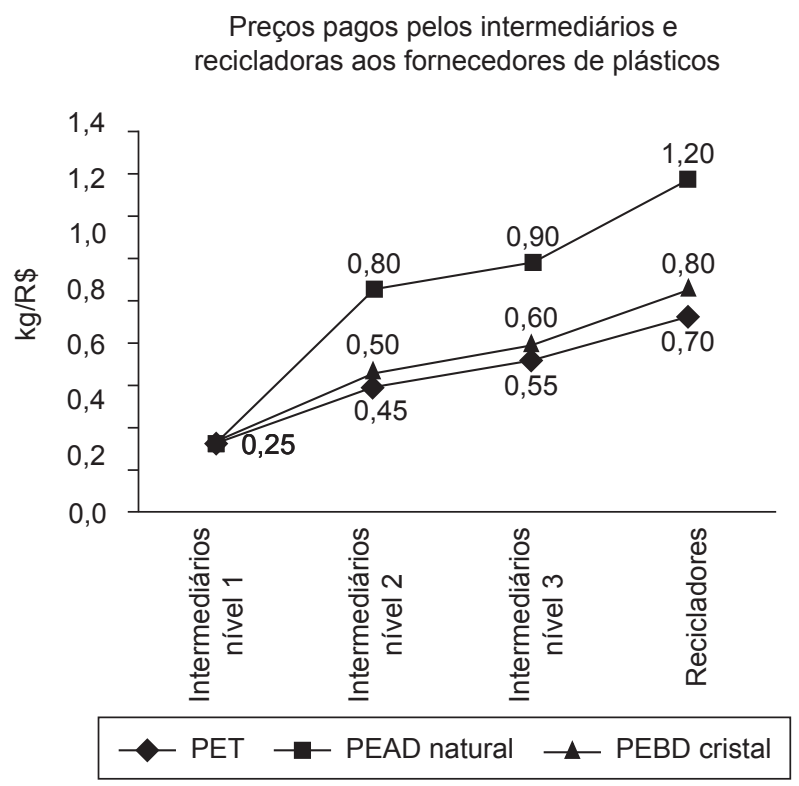

Figura 4. Preços pagos aos fornecedores de plásticos.
Após observar as características dos diversos integrantes da cadeia, desde os catadores até as indústrias recicladoras, destacaram-se os seguintes fatores, determinantes no desenvolvimento de um integrante da cadeia produtiva reversa de pós-consumo. São eles: 1) quantidade de material processada; 2) infraestrutura e equipamentos; 3) atividades realizadas; 4) capital de giro; 5) emissão de nota fiscal; 6) qualidade do material; e 7) capacidade administrativa.

\section{B - Avaliação da possibilidade da associação dos coletores de materiais recicláveis avançar na cadeia produtiva reversa de pós-consumo}

Observando-se as quantidades de materiais processadas pela associação dos coletores de materiais recicláveis - ACMR, presente na Tabela 1 , e as exigências quantitativas das indústrias recicladoras para compra de materiais, presente no Quadro 4, verifica-se que a associação teria condições de comercializar papéis, plásticos e metais ferrosos com as recicladoras. Vendendo-se esses materiais para indústrias, agregam-se valores respectivamente em 39\%, 99\% e 14\%. A valorização dos papéis, plásticos e metais ferrosos comercializados pela ACMR aumentaria seus ganhos em $48 \%$.

Considerando-se que a ACMR não tem condições de comercializar todos os seus produtos para recicladoras, constata-se que a associação não pode ser classificada como intermediário nível 3. Para que a ACMR possa ser classificada como um intermediário nível 2, vendendo materiais para mais de uma recicladora, ela terá que passar por grandes mudanças. Isto porque será necessário realizar atividades que hoje não são realizadas, adequar sua infraestrutura, adquirir equipamentos, melhorar a qualidade de seus produtos, possuir crédito para financiar capital de giro, emitir nota fiscal, e desenvolver sua capacidade administrativa.

\section{C - Avaliação da possibilidade da associação derecicladores esperança e da associação pró-criar, reciclar, educar e preservar avançarem na cadeia produtiva reversa de pós-consumo}

$\mathrm{O}$ fator principal que limita o avanço dessas associações é a quantidade de materiais processados, como pode ser observado na Tabela 1, visto que individual-

Tabela 1. Quantidades de materiais processados pelas associações.

\begin{tabular}{lrcrrr}
\hline & AREsp & Aparecida & ACMR & Pró-CREP & \multicolumn{1}{c}{ Total } \\
\hline Papéis & 11.130 & 26.100 & 180.500 & 1.442 & 219.172 \\
Plásticos & 4.668 & 11.281 & 35.000 & 1.101 & 52.050 \\
Alumínios & 320 & 420 & 780 & 61 & 1.581 \\
Vidros & 24.000 & 23.000 & 5.000 & 1.000 & 53.000 \\
Aço & 4.000 & 2.700 & 10.000 & 697 & 17.397 \\
Total & 44.118 & 63.501 & 231.280 & 4.301 & 343.200 \\
\hline
\end{tabular}

Jun/2006. 
mente elas não atendem às exigências de quantidade mínima de material a ser fornecido para recicladoras, como pode ser observado no Quadro 4. Porém esse não seria o único fator limitante que precisa ser superado, visto que as associações não possuem capacidade administrativa adequada. Os fatores emissão de nota fiscal e capital de giro são mais facilmente superados. Os fatores mais favoráveis ao avanço da associação de recicladores esperança-AREsp e da associação pró-criar, reciclar, educar e preservar - Pró-CREP na cadeia seria as atividades realizadas e a qualidade dos materiais.

\section{D - Avaliação da possibilidade da associação comunitária aparecida de reciclagem de lixo avançar na cadeia produtiva reversa de pós-consumo}

Analisando-se as quantidades de materiais processadas pela associação comunitária aparecida de reciclagem de lixo, presente na Tabela 1, e as exigências quantitativas das indústrias recicladoras para compra de materiais, presente no Quadro 4, verifica-se que a associação teria condições de comercializar papéis com as recicladoras. A agregação de valor aos papéis comercializados pela associação seria de 50\%, representando um aumento de ganhos de $16 \%$.

Considerando-se que a associação comunitária aparecida de reciclagem de lixo tem potencial, em termos de quantidade de material, para realizar comércio com indústrias recicladoras de papel, verifica-se que ela pode vir a ser classificada como intermediário nível 2. Mas, para que a associação avance na cadeia ela precisa superar várias limitações, tais como sua infraestrutura inadequada e a falta de equipamentos, bem como precisa providenciar a emissão de nota fiscal, a obtenção de capital de giro e a melhoria da capacidade administrativa. Os fatores que contribuem para o avanço na cadeia são as atividades realizadas e a qualidade dos materiais.

\section{E - Avaliação da possibilidade das associa- ções de catadores organizadas em rede avan- çarem na cadeia produtiva de pós-consumo}

Analisando-se as quantidades de materiais processadas pelas associações, apresentadas na Tabela 1, e as exigências das recicladoras sobre as quantidades mínimas de materiais compradas por carga apresentadas no Quadro 4, verifica-se que os materiais papéis, plásticos e metais ferrosos podem ser vendidos pelas 4 associações para indústrias recicladoras.

No caso da viabilização dessa comercialização, as associações poderiam ser classificadas como intermediário nível 2 e poderiam agregar valor aos seus produtos, conforme apresentado na Tabela 2.

\subsection{Proposição de organização logística}

O padrão organizacional indicado para as associações de catadores de materiais recicláveis da grande
Florianópolis é o de rede. Em várias regiões metropolitanas do País, os catadores estão se organizando desta forma. Mas há motivos relacionados às propriedades desse padrão organizacional que estimulam a formação da rede por parte das associações (WWF-BRASIL, 2003). Considerando-se que essas entidades são autônomas e não há entre elas interesse e diferenças de poder suficientes para ocorrer subordinação, e, levando-se em conta a capacidade de uma rede operar sem hierarquia (horizontalmente), de auto regular-se e auto organizar-se, espera-se que esse padrão organizacional seja apropriado às associações de catadores de materiais recicláveis.

A organização em rede facilita a obtenção de várias vantagens às associações devido à união delas em torno de objetivos comuns. Uma rede de associações de catadores de materiais recicláveis na região da grande Florianópolis pode viabilizar: a troca de informação entre seus integrantes, o estabelecimento e a condução de processos de interlocução e negociação políticas, a realização e o acompanhamento de políticas públicas, a promoção de processos de formação e capacitação, a realização de campanhas públicas de sensibilização e esclarecimento, a captação e distribuição de recursos, a prestação de serviços e o bem como desenvolvimento de atividades de produção e comercialização.

A proposta de organização logística indicada para formação de uma rede de associações de catadores na região da grande Florianópolis tem como base as organizações de catadores articuladas por uma organização de $2^{\circ}$ grau, denominada âncora, que as congregará e as representará, conforme ilustrado na Figura 5. No presente estudo, considerou-se essa organização de $2^{\circ}$ grau como uma associação, porém outra forma de personalidade jurídica que poderia ser utilizada para desenvolvimento da organização em rede é a cooperativa.

A associação âncora deve ser formada paritariamente por representantes de cada uma das associações de catadores, que por sua vez compõem uma diretoria e um conselho fiscal. É importante que a diretoria tenha, a princípio, o apoio de assessores para o desenvolvimento de suas funções, que são entre outras: a comercialização, o transporte, e o controle de qualidade e quantidade de materiais recicláveis.

Nesta proposta de organização logística, considerou-se que a organização de $2^{\circ}$ grau deva ter infraestrutura que

Tabela 2. Agregação de valor no caso das associações se organizem em rede.

\begin{tabular}{lcccc}
\hline & ACMR & AREsp & Aparecida & Pró-CREP \\
\hline Papel & $39 \%$ & $67 \%$ & $50 \%$ & $63 \%$ \\
Plástico & $99 \%$ & $52 \%$ & $18 \%$ & $44 \%$ \\
Ferro & $14 \%$ & $14 \%$ & $14 \%$ & $25 \%$ \\
Alumínio & $0 \%$ & $0 \%$ & $0 \%$ & $0 \%$ \\
Vidro & $0 \%$ & $0 \%$ & $0 \%$ & $0 \%$ \\
Global & $48 \%$ & $36 \%$ & $25 \%$ & $34 \%$ \\
\hline
\end{tabular}


permita a centralização dos materiais recicláveis, já triados e prensados pelas associações de catadores, para realizar a comercialização com as indústrias recicladoras. Destaca-se que outra forma de logística poderia ser indicada, visto que há redes de organização de catadores que não realizam a centralização física dos materiais recicláveis para realização da comercialização em conjunto.

O fluxo de informações na rede pode ocorrer por meio de reuniões periódicas entre os integrantes da organização de $2^{\circ}$ grau, bem como entre esses e suas respectivas bases. O fluxo de informações também deve acontecer por meio de telefone, principalmente para repasse de dados relacionados à quantidade, à qualidade e ao transporte de materiais. A partir do momento que os integrantes das associações desenvolverem a habilidade de utilizar ferramentas computacionais, outras tecnologias da informação poderão ser utilizadas, tais como a internet.

Após a realização das vendas dos materiais, os valores repassados pelas indústrias recicladoras à associação âncora precisam ser repassados para as associações de base proporcionalmente às quantidades emitidas. $\mathrm{O}$ fluxo de valores pode ocorrer por meio de transferência bancária. Considerando-se que as indústrias recicladoras pagam seus fornecedores com prazos, a associação âncora precisará obter capital de giro no mercado financeiro. Além de trabalhar com banco, a organização de $2^{\circ}$ grau necessitará enviar nota fiscal, visto que essa é uma exigência legal nesse tipo de transação comercial.

A princípio, as associações organizadas em rede possuem maiores condições de comercializar papéis e plásticos diretamente para indústrias devido à facilidade de consolidação e transporte desses tipos de materiais, bem como pela facilidade de atendimento das exigên-

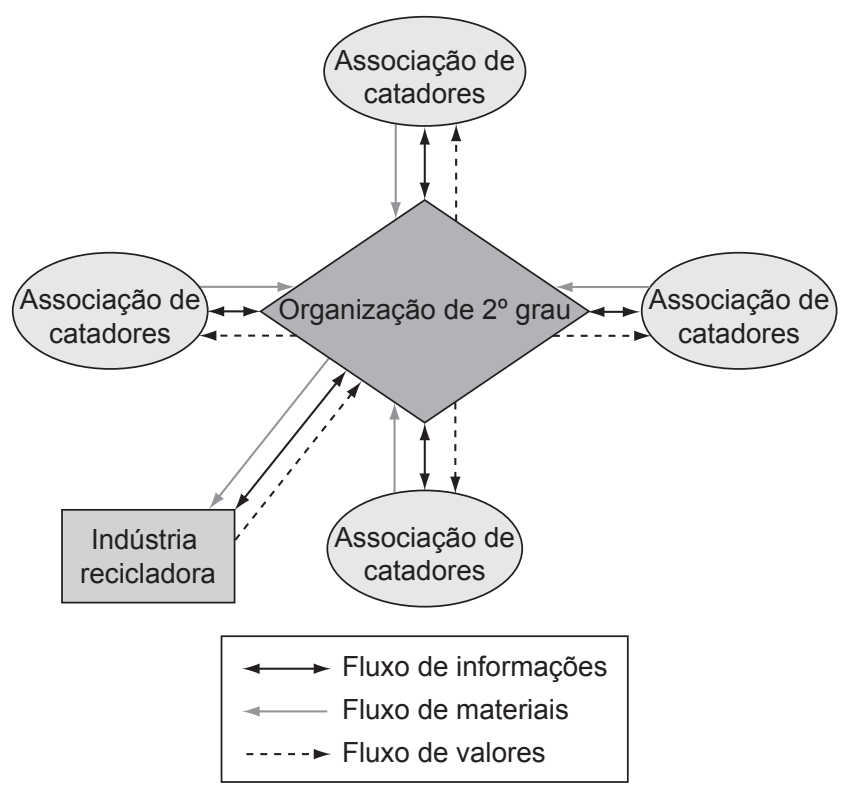

Figura 5. Proposta de organização logística para formação da rede de associações de catadores de materiais recicláveis da região da grande Florianópolis. cias por parte das indústrias em relação à quantidade e à qualidade de material. Outro tipo de produto que pode ser vendido pela Rede às indústrias é o metal ferroso, porém a baixa agregação de valor no caso da realização dessa comercialização e as dificuldades para consolidação e transporte desse material não são muito compensatórias. Então, a princípio, seriam os plásticos e os papéis que precisariam ser centralizados na associação âncora para comercialização com as indústrias. Assim, os demais materiais serão vendidos para intermediários, a partir de cada associação, porém a negociação será realizada via Rede para obterem-se melhores preços devido ao maior poder de negociação.

O estudo de viabilidade econômica da rede de associações de catadores na região da grande Florianópolis, sintetizado no Quadro 5, mostra que o empreendimento proposto é viável economicamente. Nestas condições, a rede obteria uma sobra mensal de $\mathrm{R} \$ 84.874$, valor superior à soma atual das partilhas dos catadores das associações consideradas, que é de $\mathrm{R} \$ 64.228 / \mathrm{m}$. Esta diferença representa uma agregação de valor aos materiais recicláveis de $32 \%$.

\section{Conclusões}

$\mathrm{Na}$ presente pesquisa, verifica-se que as associações de catadores de materiais recicláveis da região da grande Florianópolis organizadas em rede têm potencial para realizar a comercialização direta de seus produtos com indústrias recicladoras. Quando atuam de forma isolada nem todas as associações têm potencial para realizar essa comercialização direta, porém atuando em rede as associações podem obter uma agregação de valor aos materiais recicláveis de aproximadamente $32 \%$. Isso indica que, quando as organizações de catadores traba-

Quadro 5. Estudo de viabilidade econômica da rede de associações de catadores de materiais recicláveis.

\begin{tabular}{|lr|}
\hline 1 Capital de investimento - Ci $(\mathrm{R} \$)$ & 2117600 \\
1.1 Equipamentos & 492600 \\
1.2 Infraestrutura & 1625000 \\
1.3 Terreno & 0 \\
2 Custos de produção - CP $(\mathrm{R} \$ / \mathrm{m})$ & 27876 \\
2.1 Energia Elétrica & 5450 \\
2.2 Coleta e transporte de materiais & 22426 \\
3 Custo de financiamento $(\mathrm{R} \$ / \mathrm{m})$ & 31232 \\
4 Receita - R $(\mathrm{R} \$ / \mathrm{m})$ & 143982 \\
4.1 Venda de materiais recicláveis & 93608 \\
4.2 Repasse pela prefeitura dos custos evitados - Ce & 50373 \\
5 Sobra - S (R $\$ / \mathrm{m})$ & 84874 \\
6 No de associados & 153 \\
7 Partilha destinada aos associados - P $(\mathrm{R} \$ / \mathrm{m})$ & 516 \\
7.1 Seguridade social $(\mathrm{R} \$ / \mathrm{m})$ & 5891 \\
\hline
\end{tabular}


lham unidas, aumenta a possibilidade de elas avançarem na cadeia produtiva reversa de pós-consumo.

Para a articulação em rede das associações de catadores de materiais recicláveis identificadas na região de estudo, indica-se a formação de uma organização de $2^{\circ}$ grau, composta pelas associações de base. Esta organização mais ampla, que no presente estudo considerou-se como tendo a personalidade jurídica de associação, deve ser composta paritariamente por representantes de cada uma das associações de catadores integradas à rede. A princípio, com o apoio de assessores, esses catadores precisam desenvolver a comercialização, o transporte, e o controle de qualidade e quantidade dos materiais recicláveis coletados, triados e prensados pelas associações de base.

No estudo de viabilidade econômica da proposta, verificou-se que é fundamental o apoio da Prefeitura para o desenvolvimento da atividade. Ela deve ceder áreas para instalações das infraestruturas necessárias, visto que o gerenciamento dos resíduos sólidos é um serviço de utilidade pública e de saneamento básico, sendo este de responsabilidade das prefeituras. Além disso, as prefeituras devem repassar às associações os custos evitados pela atividade desenvolvida pelos catadores de materiais recicláveis.

Para que a rede seja formada e aconteça a comercialização direta com indústrias recicladoras, as associações devem se articular e melhorar alguns fatores indicados no estudo como sendo determinantes para o desenvolvimento e desempenho de um integrante da cadeia produtiva reversa de pós-consumo. Esses fatores originam-se da necessidade das associações atenderem às exigências impostas pelas indústrias, relacionadas principalmente à quantidade e qualidade mínimas do material a ser fornecido, à obrigatoriedade de emissão de nota fiscal e aos prazos de pagamentos geralmente realizados, bem como pela necessidade de adequação da infraestrutura de equipamentos para a realização das atividades da profissão de catador.

Através da caracterização dos resíduos sólidos e de seu gerenciamento na região da grande Florianópolis, verificou-se que, apesar da expressiva quantidade de resíduos sólidos encaminhados para reciclagem, ainda são enterrados aproximadamente $70 \%$ em peso da quantidade de materiais recicláveis gerados. Para recuperar esses materiais recicláveis dispostos em aterro sanitário, faz-se necessário desenvolver o mercado da reciclagem (REINFELD, 1994). Para tanto é fundamental que o Estado assuma seu papel de agente promotor e regulador, instituindo e implementando primeiramente uma Política Nacional de Resíduos Sólidos (CALDERONI, 1999), que, entre outras medidas, responsabilize as empresas produtoras de embalagens pelos seus resíduos, tendo como base o princípio do "poluidor pagador". Dessa forma, os serviços de coleta seletiva desenvolvidos pelos catadores, organizados em associações ou cooperativas, podem ser financiados, melhorando as condições de trabalho e vida dos catadores e aumentando os índices de reciclagem através da ampliação dos serviços prestados.

Independente da implantação dessa medida, é fundamental a inclusão dos catadores de materiais recicláveis no sistema de gerenciamento de resíduos sólidos municipais ou regionais (JACOBI, 2006; MEDINA, [199?]), utilizando-se como estratégias a formação de associações articuladas em rede. Essa forma de organização considera as condições sócio-econômicas da região da grande Florianópolis, apoiando o serviço de coleta seletiva já desenvolvida pelos catadores e estimulando a ampliação dos índices de reciclagem através da melhoria das condições de trabalho e vida desses profissionais.

\title{
Organizing a network of scavenger cooperatives in the reverse production chain of the metropolitan area of florianopolis: an alternative for aggregating value
}

\begin{abstract}
This paper describes a research carried out with members of the reverse production chain in the metropolitan area of Florianopolis, Santa Catarina, Brazil. The research aimed at proposing logistics for scavenger cooperatives to sell their products directly to recycling industries with a view to aggregating value. The results show that organizing the scavenger cooperatives in a network enable them to sell their products directly to recycling industries and increase the value of their products in $32 \%$.
\end{abstract}

Keywords: Scavenger. Recyclable materials. Network. Reverse logistics. 
AQUINO, I. F. Proposição de uma rede de associações de catadores na região da grande Florianópolis: alternativa de agregação de valor aos materiais recicláveis. Florianópolis, 2007. Dissertação (Mestrado em Engenharia Ambiental) Universidade Federal de Santa Catarina.

CALDERONI, S. Os bilhões perdidos no lixo. 3 ed. São Paulo: Humanistas, 1999.

COMPANHIA MELHORAMENTOS DA CAPITAL. Caracterização física dos resíduos sólidos urbanos de Florianópolis. Florianópolis: [s.n], 2002.

CONCEIÇÃO, M. M. Os empresários do lixo: um paradoxo da modernidade. Campinas, SP: Átomo, 2003. 193 p.

GONÇALVES, P. A reciclagem integradora dos aspectos ambientais, sociais e econômicos. Rio de Janeiro: DP\&A; FASE, 2003. 182 p. (Série Economia Solidária).

LEITE, P. R. Logística reversa: meio ambiente e competitividade. São Paulo: Prentice Hall, 2003.

JACOBI, P. (Org.). Gestão compartilhada dos resíduos sólidos no Brasil: inovação com inclusão social. São Paulo: Annablume, 2006.
MEDINA, M. Globalization, development, and municipal solid waste management in third world cities. Tijuana, Mexico: El Colegio de la Forntera Norte, [199-?]. Disponível em: <http://www.gdnet.org/pdf/2002AwardsMedalsWinners/ OutstandingResearchDevelopment/martin_medina_martinez_ paper.pdf>. Acesso em: 20 fev. 2006.

REINFELD, N. V. Sistemas de reciclagem comunitária: do projeto à administração. Tradução de José Carlos B. dos Santos. São Paulo: Makron Books, 1994. 285 p.

RODRIGUEZ, C. À procura de alternativas econômicas em tempos de globalização: o caso das cooperativas de recicladores de lixo na Colômbia. In: SANTOS, S. B. et al. Produzir para viver: os caminhos da produção não capitalista. Rio de Janeiro: Civilização Brasileira, 2002.

SCHMID, A. L. Introdução à metodologia da pesquisa. Paraná: UFPR, 2006. Disponível em: <burle.arquit.ufpr.br/ alschmid/ novo/TA053/TA053_06_2006.ppt >. Acesso em: dez. 2006.

WWF-Brasil. Redes: uma introdução às dinâmicas da conectividade. Brasília, 2003. Disponível em: http://www. esacam.edu.br/jornal/cabecalho_artigo.cfm?target=artigo/ mensuracao.htm. Acesso em: $26 \mathrm{dez} 2006$.

\section{Sobre os autores}

\section{Israel Fernandes de Aquino}

Eng $^{\circ}$ Sanitarista e Mestre em Engenharia Ambiental pela Universidade Federal de Santa Catarina - UFSC,

Departamento de Engenharia Sanitária e Ambiental - CTC, Universidade Federal de Santa Catarina - UFSC,

CP 478, Florianópolis, SC, CEP 88010-970 - Brasil,

e-mail: israelaquino@ hotmail.com

\section{Armando Borges de Castilho Jr.}

Eng $^{\circ}$ Sanitarista pela Universidade Federal de Santa Catarina - UFSC,

Doutor em Gestão e Tratamento de Resíduos pelo Institut National dês Sciences Appliquèes de Lyon, França,

Pós-doutorado pela Ecole Nationale Supérieure dês Mines de Paris - ISIGE/ENSMP,

Universidade Federal de Santa Catarina - UFSC,

Bairro Trindade, Florianópolis, SC, Brasil, CEP 88040-970

\section{Thyrza Schlichting De Lorenzi Pires}

Bióloga, Mestre em Engenharia Ambiental pela Universidade Federal de Santa Catarina - UFSC,

Professora do Departamento de Saúde e Serviços do Centro Federal de Educação Tecnológica de Santa Catarina CEFET/SC,

Universidade Federal de Santa Catarina - UFSC,

Bairro Trindade, Florianópolis, Santa Catarina, Brasil, CEP 88040-970 